\title{
RETRACTED ARTICLE: Further Pieces of Evidence to the Pulmonary Origin of Sevoflurane Escaping to the Operating Room During General Anaesthesia
}

\author{
Zhanhong Xu • Min Dong • Ran Dong • \\ Shuyan Li $\cdot$ Shangjin Cui
}

Published online: 13 June 2014

(c) Springer Science+Business Media New York 2014

The authors retract this article as it has plagiarized following article: Endotracheal tube cuff inflation with and without a pressure gauge to minimise sevoflurane pollution during intermittent positive pressure ventilation. Bela
Tanko, Bela Fulesdi, Laszlo Novak, Csaba Peto and Csilla Molnar. Eur J Anaesthesiol 31:172-180. Published online 27 November 2013.

Z. Xu $\cdot$ R. Dong $\cdot$ S. Li

The First Affiliated Hospital of Harbin Medical University,

Harbin 150001, China

M. Dong

The Affiliated Hospital of Guilin Medical University,

Guilin 541001, China

S. Cui $(\bowtie)$

State Key Laboratory of Veterinary Biotechnology, Harbin

Veterinary Research, Institute of Chinese Academy of

Agricultural Sciences, Harbin 150001, China

e-mail: drshangjincui@163.com 